\title{
Empowerment of Haranggaol Subdistrict community, Haranggaol Horison District, Simalungun Regency, North Sumatra in efforts to improve local wisdom
}

\author{
Fajar Utama Ritonga ${ }^{1 *}$, Matias Siagian ${ }^{1}$, Indra Masmur ${ }^{2}$ \\ ${ }^{1}$ Faculty of Social Science and Political Science, University Sumatera Utara, Medan \\ ${ }^{2}$ Departemen Chemistry, Faculty of Math and Science, University Sumatera Utara, Medan \\ *Email: fajar.utama@usu.ac.id
}

\begin{abstract}
The Collaborative Work Lecture with BKS West PTN is one of the community service programs conducted by 20 state universities where the University of North Sumatra is the host of the program. In the KKN program, we realize one of the tri dharma of higher education namely community empowerment. The aim of this program is that students are expected to gain learning experience through involvement in the community who directly find, formulate, solve and overcome problems that are in the field. The Community Service Program that we carry out is devoted to the community in Haranggaol Village, Haraggaol Horison District, Simalungun Regency, North Sumatra Province with the program "Community Empowerment of the Haranggaol Village, Haranggaol Horison District, Simalungun Regency, North Sumatra Province in an Effort to Improve Local Wisdom and Ecotourism in the Region of North Sumatra. This program is expected to be able to contribute to the community in the form of helping improve basic facilities and infrastructure as well as increasing the human resources available in the Haranggaol Basin so that local wisdom and ecotourism are of higher quality and help local communities maintain natural resources so that they are sustainable
\end{abstract}

Keyword: Local Wisdom, KKN, Haranggaol Village

\begin{abstract}
Abstrak
Kuliah Kerja Nyata Bersama BKS PTN Barat merupakan salah satu program pengabdian mahasiswa kepada masyarakat yang diselenggarakan oleh 20 Perguruan Tinggi negeri dimana Universitas Sumatera Utara sebagai tuan rumah pelaksana. Pada program KKN tersebut kami merealisasikan salah satu tri dharma perguruan tinggi yaitu pemberdayaan masyarakat. Tujuan dari pelaksanaan program ini yaitu diharapakan mahasiswa memperoleh pengalaman belajar melalui keterlibatan dalam masyarakat yang secara langsung menemukan, merumuskan, memecahkan dan menanggulangi permasalahan yang berada di lapangan. Kegiatan KKN yang kami laksanakan dikhususkan untuk masyarakat di Kelurahan Haranggaol, Kecamatan Haraggaol Horison, Kabupaten Simalungun, Provinsi Sumatera Utara dengan program "Pemberdayaan Masyarakat Kelurahan Haranggaol, Kecamatan Haranggaol Horison, Kabupaten Simalungun, Provinsi Sumatera Utara dalam Upaya Meningkatkan Kearifan Lokal dan Ekowisata Daerah".Program ini diharapkan mampu memberikan kontribusi terhadap masyarakat berupa membantu memperbaiki sarana dan prasarana dasar beserta meningkatkan sumber daya manusia yang ada di Keluarahan Haranggaol agar kearifan lokal dan ekowisata yang lebih berkualitas serta membantu masyarakat lokal menjaga sumber daya alam agar lestari.
\end{abstract}

Kata Kunci : Kearigan Lokal, KKN, Desa Haranggaol

\section{PENDAHULUAN}

Kuliah Kerja Nyata (KKN) pada hakekatnya merupakan perwujudan dari salah satu Tridarma Perguruan Tinggi, yakni mengabdi kepada masyarakat yang bersifat lintas disiplin (interdispliner) dan merupakan komponen keilmuan, teknologi dan seni secara aplikatif guna membantu kehidupan masyarakat, utamanya di pedesaan. Dengan KKN diharapkan para mahasiswa dapat 
Fajar Utama Ritonga et.al Empowerment of Haranggaol Subdistrict community

membantu masyarakat dalam menghadapi kesulitan-kesulitan yang dihadapi sesuai dengan bidang keilmuan masing-masing. Melalui KKN ini pula mahasiswa dapat membantu merealisasikan program-program pemerintah dalam rangka melaksanakan pemerataan pembangunan di pedesaan.

KKN merupakan suatu kegiatan yang dirasa penting baik bagi mahasiwa maupun masyarakat. Bagi mahasiswa, KKN merupakan aktivitas belajar yang dilakukan lintas keilmuan dalam menggali, menghayati dan mencari solusi masalah-masalah pembangunan masyarakat di pedesaan. Bagi masyarakat desa, KKN diharapkan dapat memberikan semangat baru untuk menggerakkan pembangunan desa. Mahasiswa setelah sarjana adalah unsur yang paling sadar dalam masyarakat. Jadi fungsi lain yang harus diperankan mahasiwa adalah sifat kepeloporan dalam bentuk dan proses perubahan masyarakat. Karenanya, kelompok mahasiswa berfungsi sebagai duta-duta pembaharuan masyarakat atau "agent of social change".

Kelurahan Haranggaol adalah sebuah desa yang terletak di Kelurahan Haranggaol, Kecamatan Haranggaol Horison, Kabupaten Simalungun. Dulunya Desa Haranggaol bernama Desa Tiga Langgiung yang artinya adalah pasar di pesisir pantai danau yang menjual berbagai jenis hasil pertanian dari desa sekitar Danau Toba. Pada tahun 1960 nama desa ini diubah menjadi Desa Haranggaol.

Memasuki wilayah perkampungan, dapat dilihat pemukiman yang bertingkat dengan bangunan papan dan beton berderet membelakangi Danau Toba. Tidak tampak seperti wilayah pedesaan Batak yang terkenal dengan rumah- rumah panggung. Memang hampir seluruh rumah di Desa Haranggaol sudah berubah menjadi rumah yang lazim dilihat diperkotaan. Haranggaol memiliki sebuah pasar tradisional bernama Tiga Langgiung yang artinya pasar di tepi danau, karena lokasinya yang berdekatan dengan danau. Dahulu pasar dibuka dua kali seminggu setiap senin dan kamis.Tetapi sekarang pasar tradisional ini dibuka sekali seminggu yakni setiap senin. Menurut warga hal ini disebabkan karena kurangnya para pedagang dari berbagai penjuru seperti dari Samosir, Silalahi, Seribu Dolok, dan Pematang Raya dan disebabkan karena maraknya masyarakat membuka keramba jaring apung di danau dan jalur kapal dan pelabuhan sudah tertutup oleh keramba dan tidak adanya hasil pertanian seperti waktu dulu ditambah merosotnya pariwisata.

Berdasarkan analisa situasi di Kelurahan Haranggaol maka permasalahan yang didapat di antaranya masih minimnya pengetahuan akan pentingnya kebersihan lingkungan yang disebabkan oleh limbah/sampah rumah tangga, pertanian, perkebunan, dan peternakan/perikanan yang dibuang sembarangan, tidak adanya penamaan jalan dan dusun, akses jalan yang sempit dengan sejumlah lubang aspal dan bebatuan, minimnya pengetahuan dan keterampilan masyarakat dalam mengolah limbah/sampah menjadi bahan daur ulang, pakan ternak, pupuk kompos, dll, minimnya pengetahuan dan keterampilan masyarakat dalam memperkenalkan wisata Kelurahan Haranggaol.

\section{METODE PELAKSANAAN}

\subsection{Persiapan dan Pembekalan}

Metode kegiatan KKN Bersama ini dalam bentuk pembekalan dari pihak USU pada tanggal 15 Juli 2019 di Auditorium USU dan dilanjutkan di aula Bupati Pematang Raya Simalungun yang disampaikan langsung oleh Bupati J.R. Saragih.

\subsection{Tahapan Pelaksanaan Kegiatan}

Pelaksanaan KKN Bersama 2019 di Kelurahan Haranggaol ini membutuhkan keterlibatan perangkat desa dan tokoh masyarakat. Pada kegiatan KKN Bersama 2019 ini program disusun secara simultan dan sistematis untuk mengembangkan kemampuan masyarakat dalam mengelola serta memanfaatkan potensi lingkungan secara mandiri untuk ekowisata berbasis kearifan lokal. Adapun tahapan utama yang dijalankan yaitu survei lokasi yang dilakukan oleh beberapa perwakilan kelompok yang berasal dari USU, selanjutnya pendekatan ke masyarakat dan sosialisasi program yang dilakukan setelah berada di lokasi dengan sasarannya adalah perangkat 
Fajar Utama Ritonga et.al Empowerment of Haranggaol Subdistrict community

kelurahan dan tokoh-tokoh masyarakat. Pendekatan kepada elemen-elemen penting masyarakat ini untuk mengkomunikasikan program-program yang akan dilaksanakan selama kegiatan KKN berlangsung yaitu 35 hari kerja. Bentuk kegiatan yang dilakukan adalah forum silaturahmi yang dilakukan dengan suasana kekeluargaan sesuai dengan kearifan lokal masyarakat Kelurahan Haranggaol.

\section{HASIL DAN PEMBAHASAN}

\subsection{Kondisi sebelum dilaksanakan KKN}

Berdasarkan hasil observasi, diskusi, wawancara, dengan aparatur Kelurahan Haranggaol dan juga masyarakat di Kelurahan Haranggaol, kelompok 18 Pengabdian KKN dapat membuat prioritas masalah dan membuat program yang sesuai dengan judul pengabdian KKN. Beberapa permasalahan yang menurut tim pengabdian menjadi prioritas dan dapat dilakukan pemberdayaan oleh kelompok 18 sebagai berikut:

\section{Bidang Pendidikan}

Masih rendahnya minat belajar anak-anak di Kelurahan Haranggaol terutama anak usia sekolah SD dan SMP, serta jauhnya sarana Bimbingan belajar di lokasi pengabdian ditambah dengan kesibukan orang tua yang bekerja sehingga kurang memperhatikan pendidikan anak-anak mereka dirumah. Disekolah minimnya tenaga guru yang ada di SMP Swasta GKPS Kelurahan Haanggaol.

2. Bidang Kebudayaan

Minimnya kesadaran budaya anak-anak di Kelurahan Haranggaol tentang budaya khususnya seni tari tradisional.

\section{Bidang Kesehatan dan Lingkungan}

Minimnya kesadaran akan kebersihan lingkungan, sampah berserakan di halaman rumah warga, di jalan, rumput yang panjang dan tidak terawat di pinggir jalan. Untuk anak-anak SD gerakan sadar kebersihan gigi dan mulut, karena banyak anak-anak SD yang giginya sudah busuk, tidak terawat karena malas menyikat gigi 2 kali sehari dan menyikat gigi dengan cara yang salah. Minimnya kesehatan untuk lansia, karena banyak lansia di Kelurahan Haranggaol yang tidak aktif bergerak seperti melakukan senam lansia.

\section{Bidang Administrasi Desa}

Belum adanya letak batas lingkungan di Kelurahan Haranggaol, belum ada nama pamplet jalan atau gang di Kelurahan Haranggaol, masyarakat masih banyak yang belum tahu keberadaan rumah kepala lingkungan dan siapa kepala lingkungan di Kelurahan Haranggaol. Gapura selamat datang yang sudah usang dan dalam rangka menyambut Kemerdekaan Republik Indonesia yang ke-74 perlu segera direnovasi sesuai dengan kesanggupan dan kearifan lokal masyarakat di kelurahan Haranggaol. 
Fajar Utama Ritonga et.al Empowerment of Haranggaol Subdistrict community

\subsection{Kondisi Sesudah dilaksanakan KKN}

\subsubsection{Bidang Pendidikan}

1. Bimbingan PAUD

Dilakukan untuk membantu ibu pendidik yang kekurangan tenaga pengajar serta mempermudah pembelajaran karena anak-anak lebih mudah dekat dengan abang dan kakak KKN. Pada Kegiatan ini anak-anak PAUD diajari menulis, membaca, menari, dan menyanyi mulai dari pukul 08.00-10.00 WIB setiap Hari Senin s/d Jumat.
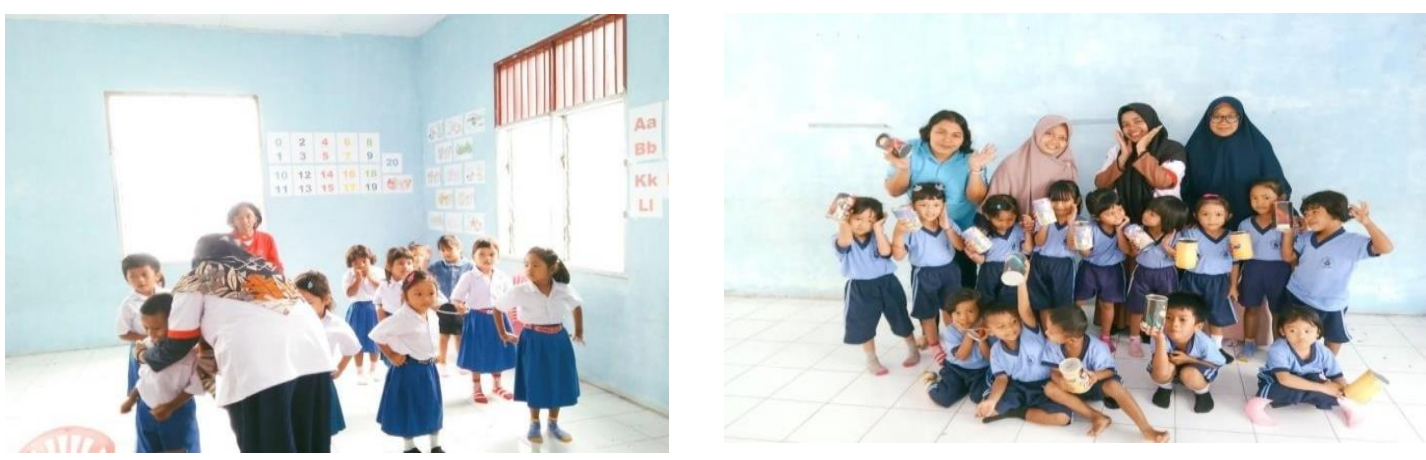

Gambar 3.1 : Bimbingan Paud

2. Membantu Guru Mengajar di SD dan SMP

Kegiatan ini diadakan di SD Negeri 091358 mulai dari Hari Senin s/d Jumat dan di SMP Swasta GKPS Haranggaol mulai dari Hari Senin s/d Sabtu sesuai dengan permintaan pihak sekolah. Adapun mata pelajaran yang diajarkan sesuai dengan mata pelajaran yang telah tertera dalam roster sekolah mulai dari pagi s/d selesai.
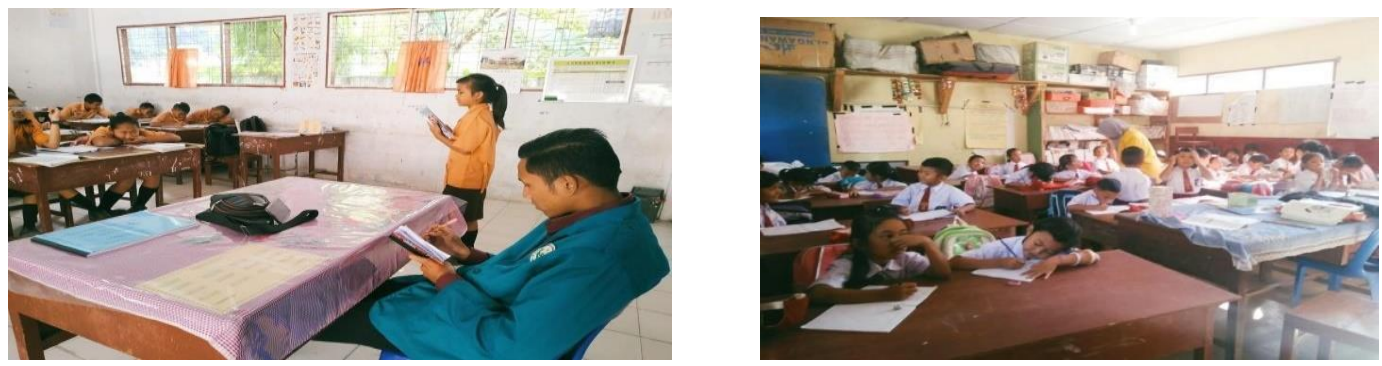

Gambar 3.2 Membantu Guru Mengajar SD \&SMP

\section{Sekolah Alam}

Kegiatan ini diadakan di depan posko KKN Bersama kelompok 18. Di sini anak belajar dari lingkungan yang ada di sekitar mereka. Dalam konsep pendidikannya sekolah alam, mamanfaatkan alam ruang belajar, media dan bahan mengajar dan sebagai objek pembelajaran. Target sekolah alam ini adalah anak SD kelas 5 yang dilaksanakan setiap Hari Senin s/d Jumat mulai pukul 15.00-17.00 WIB. 

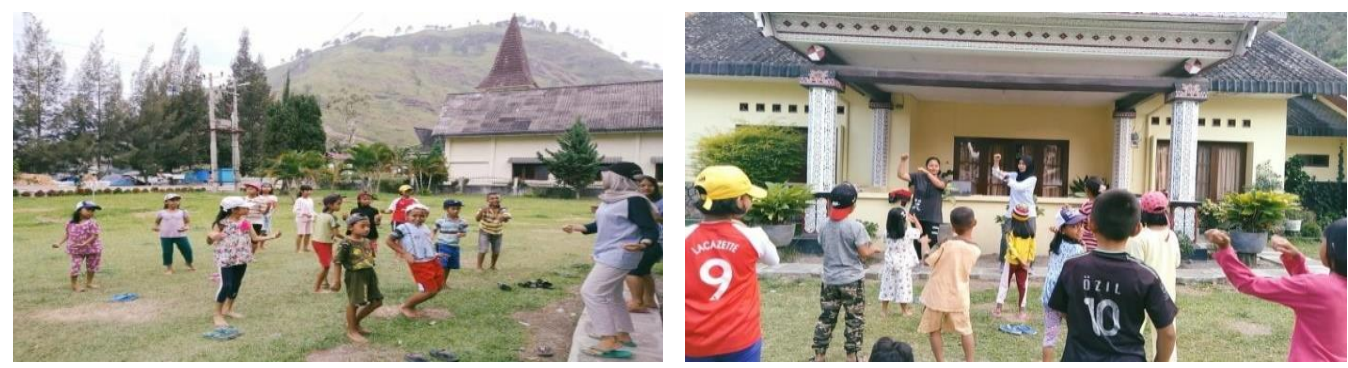

Gambar 3.3 Sekolah Alam

4. Bimbingan Belajar Lintas Haranggaol SMP

BLH merupakan salah satu program kerja yang berfokus dalam memberikan bimbingan belajar, mengembangkan minat belajar, dan memotivasi murid dengan cara yang menyenangkan dan berbeda dari kegiatan pembelajaran murid di sekolah. Mata pelajaran yang diajarkan adalah matematika dan Bahasa Inggris sesuai dengan permintaan sekolah. Adapun target BLH adalah siswa-siswi Kelas IX ${ }^{1}$ dan IX ${ }^{2}$ SMP Swasta GKPS Haranggaol yang akan menghadapi Ujian Nasional. BLH dilaksanakan pada setiap Hari Kamis dan Jumat sepulang sekolah pada pukul 15.00 s/d selesai di SMP Swasta GKPS Haranggaol.
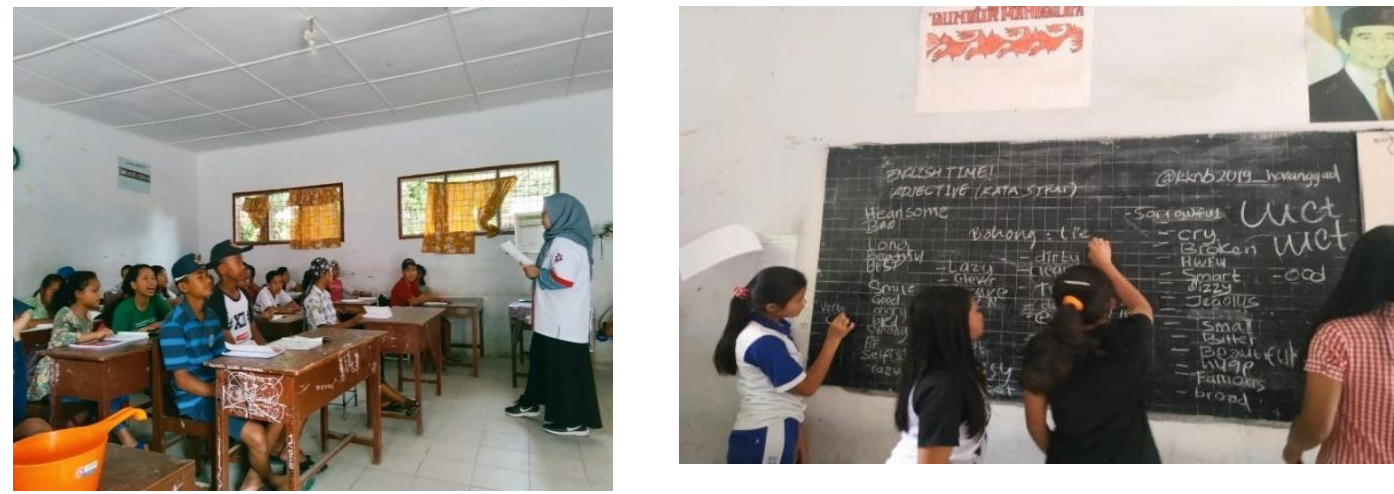

Gambar 3.4 Bimbingan Belajar Lintas Haranggaol SMP

\subsubsection{Bidang Kebudayaan}

Pelatihan Tari di SMP

Dalam bidang kesenian ini difokuskan kepada anak-anak SMP Swasta GKPS Haranggaol. Kegiatan ini dilakukan untuk menyadarkan anak-anak bahwa tari tradisional sangat penting di pahami sejak dini agar mereka bisa tetap melestarikan kebudayaan daerah mereka dan tidak melupakannya. Pelatihan tari di laksanakan setiap Hari Senin s/d Jumat pukul 02.00 03.30 IB di posko KKN Bersama kelompok 18. 
Fajar Utama Ritonga et.al Empowerment of Haranggaol Subdistrict community

\subsubsection{Bidang Kesehatan dan Lingkungan}

1. Aksi Bersih Haranggaol

Kegiatan ini dilaksanakan setiap Hari Jumat, ditempat yang berbeda-beda seperti didepan kantor kelurahan, jalan besar Haranggaol, dan rumah warga. Tujuan kegiatan ini adalah memberikan pemahaman sekaligus ajakan kepada masyarakat untuk melakukan gerakan hidup bersih dan sehat, membantu pemerintah dalam mensosialisasikan dan mewujudkan program pelayanan kebersihan lingkungan, membantu meringankan beban masyarakat kita yang membutuhkan, meningkatkan dan mewujudkan semangat keperdulian terhadapa sesama
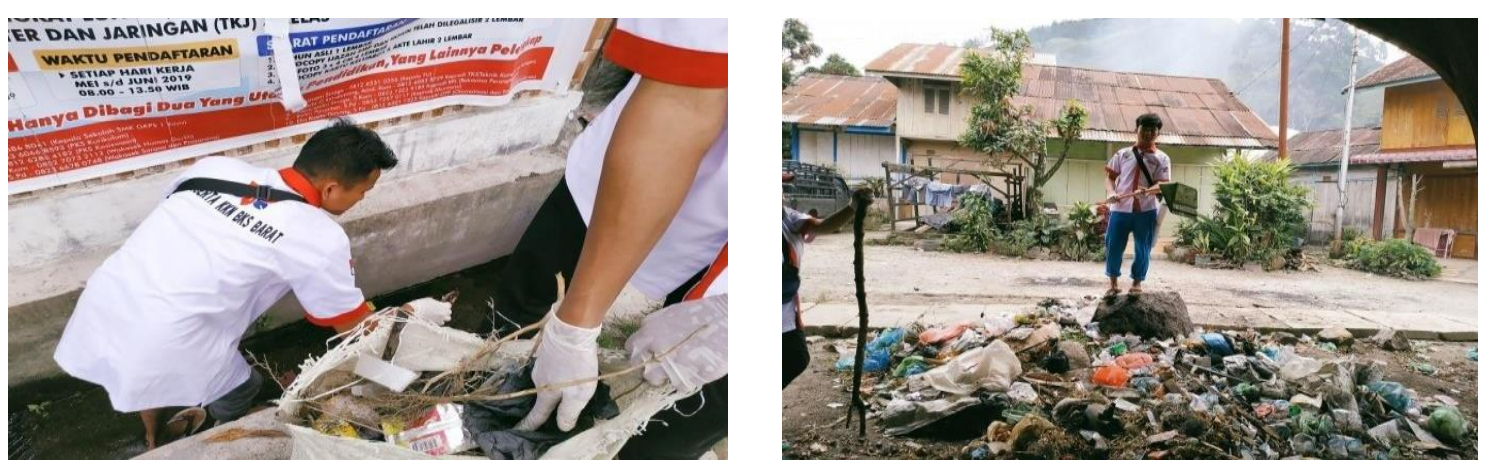

Gambar 3.5. Aksi Bersih Haranggaol

2. Penyuluhan Kebersihan Gigi dan Mulut

Kegiatan ini terlaksana di SD Negeri 095163, dengan sasaran kegiatan murid kelas 1 sampai kelas 3 yang berjumlah 80 siswa. Tema kegiatan ini adalah "Menciptakan Generasi Indonesia Yang Bersih dan Sehat Dimulai dari Kebersihan Gigi dan Mulut". Kegiatan ini dilakukan pada Hari Rabu, 7 Agustus 2019. Adapun tujuan dari ini yaitu meningkatkan pengetahuan kepada siswa mengenai makanan yang baik untuk kesehatan gigi dan makanan merusak kesehatan gigi dan memberikan pemahaman serta motivasi kepada siswa agar rajin merawat dan memelihara kebersihan gigi melalui kegiatan praktik sikat gigi bersama dilapangan. Harapan kami murid SD Negeri 095163 mempunyai semangat untuk senantiasa merawat kesehatan gigi dan mulutnya melalui sikat gigi setiap hari.
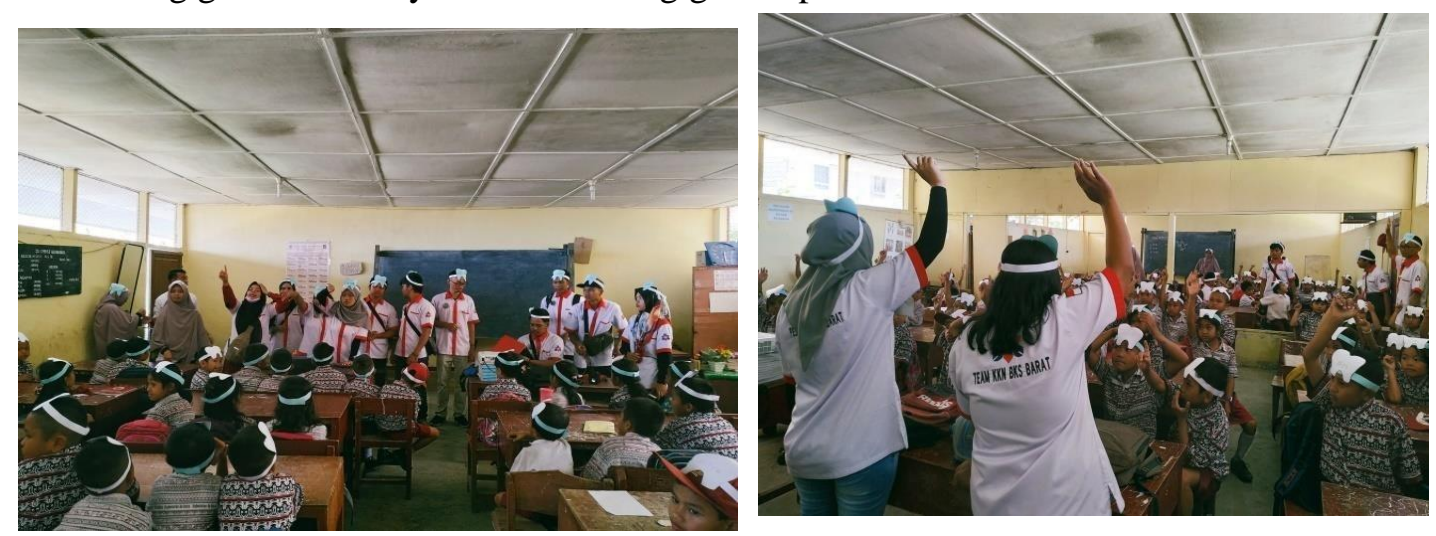

Gambar 3.6. Penyuluhan Gigi dan Mulut 
Fajar Utama Ritonga et.al Empowerment of Haranggaol Subdistrict community

\subsubsection{Bidang Administrasi Desa}

1. Pembuatan Plang Jalan

Dilaksanakan bersama-sama dengan kelompok $15 \mathrm{KKN}$ Bersama dengan tujuan memberikan letak batas setiap lingkungan serta mengetahui lokasi kepala lingkungan di Kelurahan Haranggaol sehingga masyarakat mengetahui sampai dimana letak batas lingkungannya dan lokasi rumah kepala lingkungannya.
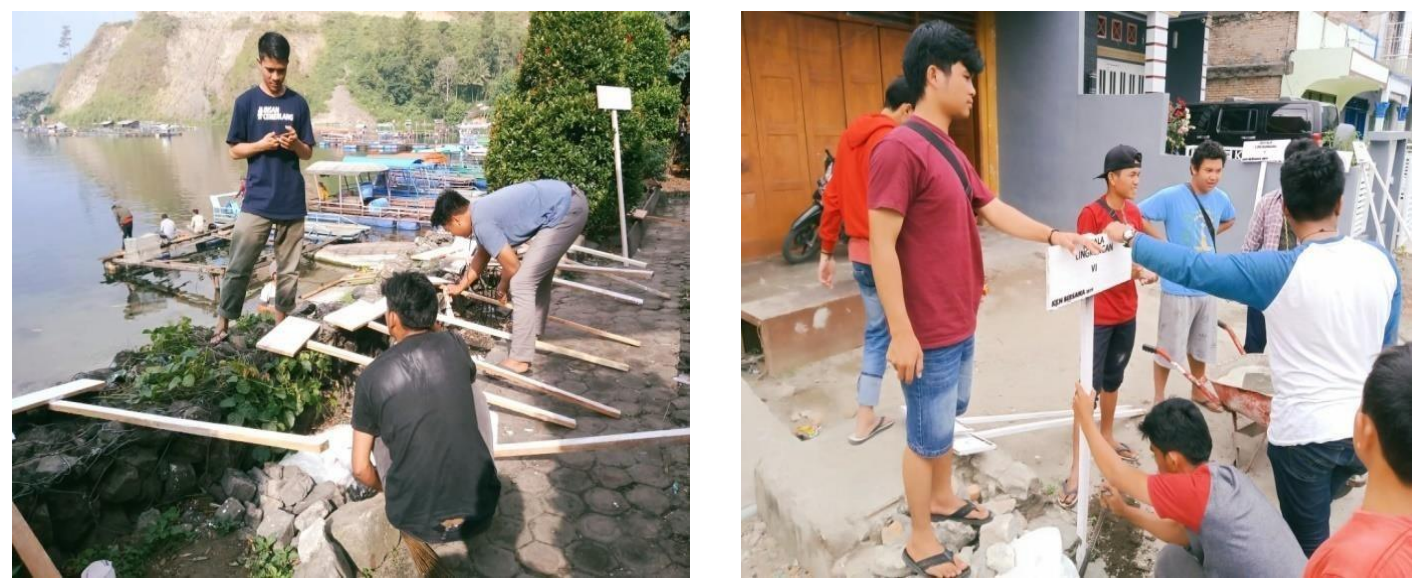

Gambar 3.7 Pembuatan Plang Jalan Batas Lingkungan

2. Pembuatan Gapura HUT ke-74 RI

Gapura dibuat bertujuan untuk menunjukan semangat para setiap warga dalam menyambut hari kemerdekaan, selain itu dengan dibuatnya gapura bisa menarik perhatian orang luar daerah yang berkunjung pada daerah tersebut. Disisi lain dengan dibuatnya gapura bisa memacu kreativitas serta kekompakan pada daerah tersebut. Namun dikarenakan kurangnya tenaga masyarakat di Kelurahan Haranggaol, mahasiswa KKN Bersama Kelompok 15 dan Kelompok 18 akhirnya bekerjasama untuk membuat gapura HUT ke-74 RI. Pembuatan gapura ini berlangsung kurang lebih 5 hari lamanya.
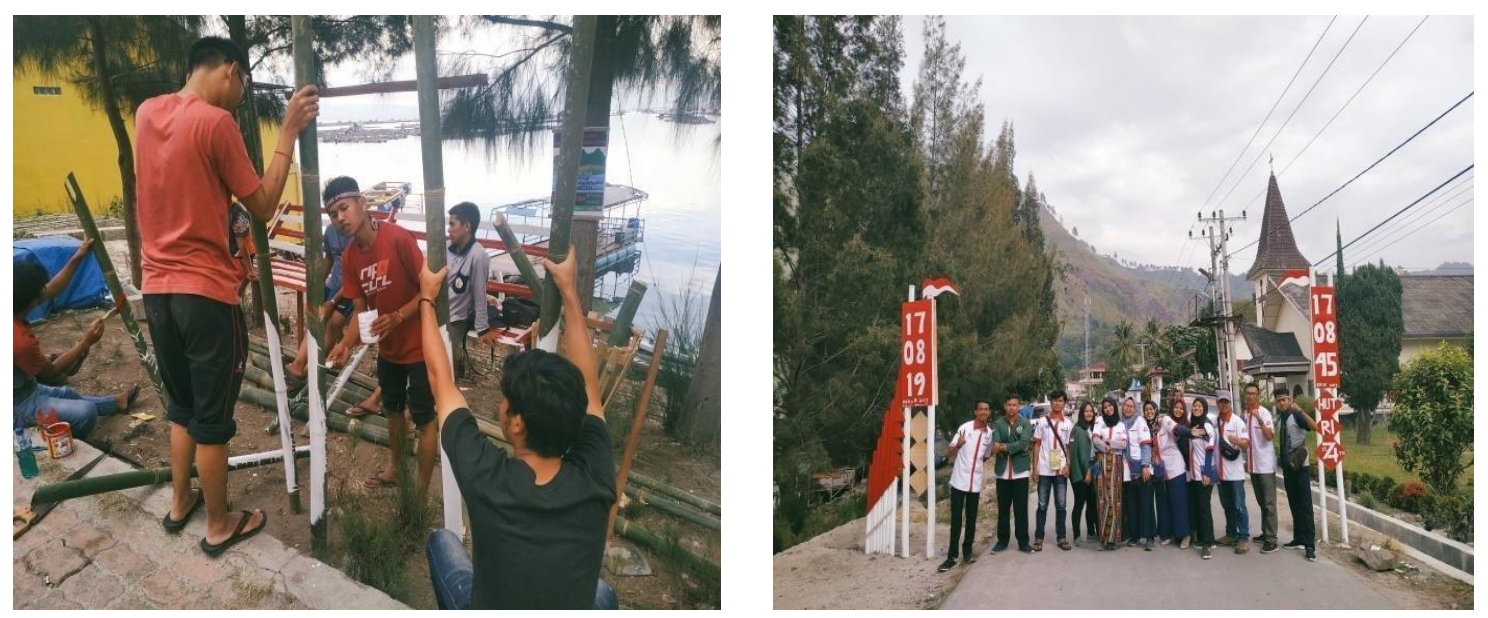

Gambar 3.8 Pembuatan Gapura HUT RI Ke 74 
Fajar Utama Ritonga et.al Empowerment of Haranggaol Subdistrict community

\section{KESIMPULAN}

Berdasarkan kegiatan yang telah dilakukan oleh Mahasiswa KKN Bersama 2019 kelompok 18 Kelurahan Haranggaol, Kecamatan Haranggaol Horison, Kabupaten Simalungun, Provinsi Sumatera Utara dapat disimpulkan beberapa permasalahan di Kelurahan Haranggaol yang telah dapat diselesaikan, yaitu:

1. Minimnya pengetahuan masyarakat dalam penggunaan dan pemanfaatan potensi Sumber Daya Alam yang ada di Haranggaol.

\section{UCAPAN TERIMA KASIH}

Tim pengabdian pada masyarakat mengucapkan terima kasih kepada pihak LPPM USU yang telah memberikan dana kepada pengabdian ini. Terima kasih juga kepada pihak mitra yang telah koopratif di dalam pelaksanaan pengabdian ini.

\section{DAFTAR PUSTAKA}

Adi, Isbandi Rukminto. (2013). Kesejahteraan Sosial (Pekerjaan Sosial, Pembangunan Sosial, dan Kajian Pembangunan). Jakarta: Rajawali Pers.

Adi, Isbandi Rukminto. (2008). Intervensi Komunitas Pengembangan Masyarakat Sebagai Upaya Pemberdayaan Masyarakat. Jakarta: Raja Grafindo.

Suharto, E., (2010). Membangun Masyarakat Memberdayakan Rakyat: Kajian Strategis Pembangunan Kesejahteraan Sosial dan Pekerjaan Sosial. Bandung: PT. Refika Adit 